\title{
FARACo, C. A. (2016). História Sociopolítica da língua portuguesa. SÃo Paulo: Parábola Editora.
}

\author{
Micaela Ramon
}

Sob o título de História sociopolítica da língua portuguesa, saiu a público, em 2016, uma importante obra da autoria de Carlos Alberto Faraco, renomado linguista brasileiro, ao tempo coordenador da Comissão Nacional do Brasil junto do Instituto Internacional da Língua Portuguesa (IILP), instituição da Comunidade de Países de Língua Portuguesa (CPLP) cujos objetivos são, de acordo com os seus estatutos, "a promoção, a defesa, o enriquecimento e a difusão da língua portuguesa como veículo de cultura, educação, informação e acesso ao conhecimento científico, tecnológico e de utilização oficial em fora internacionais"'.

Gozando o autor de reputação quer nos meios académicos, quer nos círculos de decisão associados às políticas de língua, a obra foi objeto de não despiciendo interesse, traduzido em várias recensões surgidas a público, sobretudo em revistas da especialidade e noutros meios de comunicação do Brasil. Reação idêntica nos restantes países da CPLP não se encontra tão facilmente documentada. A publicação, porém, merece toda a atenção por parte de quantos se interessem pelas questões da língua, sua formação, expansão, transformação e situação atual.

O título dado à obra deixa antever o seu conteúdo. Trata-se, de facto, de uma história da língua portuguesa elaborada não a partir do ponto de vista da linguística interna, mas antes adotando a perspetiva da linguística externa. O próprio autor, no texto de "Apresentação" do livro, esclarece a distinção entre tais conceitos, explicitando, do mesmo passo, os propósitos que o guiaram na sua elaboração:

são muitas as perspectivas pelas quais se pode investigar a história de uma língua. A mais comum tem sido a que procura descrever as mudanças dos diversos subsistemas que compõem sua organização estrutural - sua fonologia, sua sintaxe, sua morfossintaxe e seu léxico. (...) Não é disso que tratamos neste livro. (...) Preocupou-nos observar como a variedade linguística românica que emergiu do latim falado no noroeste da Península Ibérica (...) se expandiu para o sul, ocupando toda a faixa ocidental da Península; e, posteriormente, na esteira da expansão marítima e do colonialismo português, deixou as fronteiras europeias, instalando-se na Ásia, na África e na América, e é hoje uma língua internacional. (pp. 9-10)

' Retirado dos Estatutos da Comunidade dos Países de Língua Portuguesa, disponíveis em http://www.cplp.org/Files/Filer/ Documentos\%20Essenciais/Estatutos_CPLP_REVLISO7.pdf 
Ainda no texto de "Apresentação" são reveladas informações sobre o método seguido por Faraco. Tal método funda-se na identificação, seleção e apresentação de "boa parte da diversidade de opiniões e concepções sobre a língua portuguesa", analisadas e discutidas sob o prisma da "suspeita e [da] crítica das narrativas" (p. 10).

Trata-se, portanto, de uma obra que não se debruça sobre as evoluções registadas a nível da estrutura da língua portuguesa enquanto sistema de signos regido por regras intrínsecas de funcionamento, mas sim de um estudo que privilegia as relações da língua com os seus falantes, no decorrer dos séculos e nos múltiplos espaços geográficos em que está presente. É, pois, uma história sociopolítica da língua portuguesa.

Carlos Alberto Faraco organiza a sua obra (fruto de reflexões que foram "tomando forma nos últimos dez ou quinze anos em decorrência do [seu] envolvimento, acidental ou intencional, com questões de política de língua", p. 11) em dois extensos capítulos, acrescidos de um terceiro, bastante mais conciso, no qual são sistematizadas algumas ideias-chave em jeito de "Conclusão".

No primeiro capítulo (pp. 14-225), intitulado "História", o autor passa em revista todo o processo de formação da língua portuguesa, desde a sua diferenciação relativamente aos restantes "falares românicos" (ou seja, os múltiplos "desdobramentos históricos do chamado latim vulgar, isto é, do conjunto de variedades de latim falado pelas populações das diferentes regiões do Império Romano", p. 14) até à sua disseminação pelos demais continentes a que as viagens marítimas empreendidas pelos portugueses a fizeram chegar. A nosso ver, três questões merecem particular destaque naquilo que concerne este capítulo: 1) a oficialização da língua; 2) as consequências linguísticas da expansão portuguesa; e 3) a criação dos principais instrumentos de fixação do seu corpus.

Relativamente à primeira questão, o autor mostra como o paulatino abandono do latim, não só, mas também em Portugal, foi motivado por questões eminentemente pragmáticas, decorrentes de necessidades prementes de comunicação que levaram, por exemplo, a que, a partir do reinado de D. Afonso II (1211-1223), "a crescente ação jurídica inovadora e a necessidade de tornar as leis conhecidas por um sempre maior número de pessoas [tenham motivado] a progressiva substituição do latim pela língua românica vernácula na redação da documentação saída da Chancelaria Real" (pp. 21-22). Motivações idênticas estiveram na base das normativas reais produzidas quer por D. Manuel I (1498), quer por D. João IV (1656), no sentido de obrigar os "médicos e cirurgiões" a "receitar aos Boticarios as purgas, xaropes e medicinas que mandarem tomar os enfermos, em linguagem portugueza, que as intendessem todos" (p. 24). Acompanhando o lento, mas inexorável, processo de utilização privilegiada da língua vernácula portuguesa em todos os contextos que hoje podem ser considerados institucionais, Faraco documenta a sua progressiva "oficialização", ainda que assuma um posicionamento crítico relativamente àquilo que considera serem "armadilhas do anacronismo (...) ou do triunfalismo" que levam alguns "estudiosos da história de Portugal e historiadores da língua" a atribuírem “a D. Dinis o gesto de transformação da língua 'portuguesa' em língua 'oficial' do reino, o que teria ocorrido em 1296" (p. 23).

No apartado dedicado à expansão da língua portuguesa, o autor começa por sintetizar o processo de internacionalização deste idioma nos seguintes termos: 
a partir de meados do século XV, a língua portuguesa, na esteira da expansão marítima de Portugal, sai de suas fronteiras europeias e se torna uma língua internacional, com falantes seus se estabelecendo em enclaves ao longo da costa ocidental e oriental do continente africano, alcançando a Índia em 1498, a América em 1500, a China em 1513, o Timor em 1515 e o Japão em 1534. (p. 57)

Uma vez mais, são apontadas razões socioeconómicas, extrínsecas à própria língua, para justificar o seu sucesso e implantação em paragens distantes do seu ponto de origem:

são a estrutura em rede, com relativamente poucas pessoas envolvidas, e a supremacia naval resultante de os navios portugueses transportarem artilharia a bordo (...) que podem explicar que um país com cerca de dois milhões de habitantes tenha sido capaz de dominar sem grande concorrência, por praticamente um século, o comércio marítimo internacional nas rotas que cobriam a costa africana e chegavam à Índia, Malaca, Timor e Macau. (pp. 58-59)

A mesma ordem de razões é invocada para explicar o retrocesso da presença do Português, a partir do século XVII, em territórios asiáticos:

com a perda dos entrepostos, retraiu-se também a presença da língua portuguesa na Ásia, que já não era grande quando do domínio português, considerando que a população que a tinha como língua primeira sempre tinha sido numericamente pouco expressiva. (p. 59)

Porém, o que mais ressalta no campo das consequências linguísticas da "expansão extraeuropeia de Portugal" é que ela "pôs os portugueses em contacto com um sem-número de línguas africanas, asiáticas e americanas" (p. 62), tendo resultado daí:

o surgimento de um pidgin e de línguas crioulas de base portuguesa; a transformação de línguas indígenas americanas em línguas coloniais (...); a emergência das chamadas variedades não nativas, decorrentes do uso do português como língua segunda (...); a consolidação, no Brasil, de uma inteira comunidade extraeuropeia em que a língua portuguesa se consolidou hegemonicamente como língua primeira no correr do século XIX. (p. 63)

A este elenco de consequências, julgamos pertinente acrescentar (embora o autor não o refira), as alterações ocorridas no próprio idioma transportado pelos portugueses, fruto desses múltiplos contactos que muito contribuíram para o enriquecimento da língua através, por exemplo, da incorporação de termos oriundos das diversas outras línguas com que o Português comunicou, muitos deles absolutamente indispensáveis para a nomeação das novas realidades até então desconhecidas.

Finalmente, no último apartado do primeiro capítulo, Faraco reflete sobre aquilo a que chama a "língua imaginária". Sob este título algo depreciativo, o autor inventaria 
as ações desenvolvidas, primeiramente em Portugal e, a partir do século XIX, no Brasil também, em prol da fixação do corpus da língua portuguesa. É assim que, recuando ao século XVI, Carlos Alberto Faraco destaca o surgimento das primeiras gramáticas, dos primeiros tratados de ortografia e dos primeiros dicionários, obras complementadas por vários "elogios" da língua portuguesa produzidos por alguns dos mais importantes vultos do Humanismo português como João de Barros, Pero de Magalhães de Gândavo, António Ferreira ou Camões.

Relativamente às obras desta natureza, Faraco assume uma posição dúbia e, quanto a nós, contraditória. Se, por um lado, avalia com suspeição crítica estas iniciativas que considera etapas do "processo de construção da língua imaginária (...) com a escrita de instrumentos que buscavam definir-lhe também um perfil enobrecido" (pp. 176-177), por outro, acompanha as vozes de quantos lastimam que "a lexicografia portuguesa [seja] uma das mais modestas entre as grandes línguas europeias" (p. 187), que haja tantas e tão frequentes hesitações em termos de estabilização de uma ortografia do Português e que não tenha sido ainda possível produzir "uma gramática ecumênica da língua“ (p. 225) na senda dos esforços encetados de forma pioneira por Celso Cunha e Lindley Cintra no último quartel do século XX. Ou seja, embora questione a legitimidade de instrumentos que adotam e traduzem uma visão "uniformizadora que paira sobre a diversidade concreta e fluida" (p. 177) da língua, acaba, no entanto, por implicitamente reconhecer a importância desses instrumentos enquanto mecanismos reguladores de políticas de língua ao nível da definição do corpus, criticando mesmo a relativa tibieza e falta de concertação com que os diversos agentes com responsabilidades para tal atuam neste domínio.

O segundo capítulo da obra (pp. 228-357), com o título "Rumo à lusofonia", é inteiramente dedicado a essa importante questão e nele assume preponderância a postura do analista comentador comprometido com uma certa visão sobre as representações identitárias da língua portuguesa que vêm sendo construídas e veiculadas, ao longo dos séculos, pelas elites dos seus usuários.

A primeira tarefa a que Faraco se dedica é a desmontar a ideia de "um Portugal maior que Portugal". Fá-lo pela via da análise dos discursos daqueles autores a quem se deve a construção de uma conceção mítica de Portugal como país dotado de uma supremacia natural que lhe reservaria um destino grandioso no seio do conclave das nações do mundo.

Começa a sua análise pela referência ao Padre António Vieira, autor que, embora não se tenha aliado à "lista dos que, antes e depois dele, escreveram elogios e defesas das 'maravilhas' da língua” (p. 235), abriu caminho, através da sua noção de Portugal e dos portugueses como reino e povo escolhidos por Deus para estabelecer o Império de Cristo na terra, às teses daqueles que defendem a existência de uma comunidade supranacional construída em torno da língua comum. Fernando Pessoa, que atribuiu a Vieira o epíteto de "Imperador da língua portuguesa", foi quem formulou "a tese de que - Quinto Império será fundamentalmente um império encarnado na língua, porque não há de ser um império material, mas cultural" (p. 235). Agostinho da Silva associa-se-lhe 
na defesa da necessidade de operar uma "revolução cultural e moral como necessária e suficiente para a reconstrução civilizacional que desembocaria num novo tempo de paz, liberdade, fraternidade e abundância para toda a Humanidade (...) a ser construído (...) pelos povos falantes da língua portuguesa" (p. 242).

Destaque é igualmente dado por Faraco à teoria do lusotropicalismo, defendida por Gilberto Freyre, assente na ideia de que o colonialismo português, por ter sido feito "não pela força bruta, não pelo poder militar, não pela superioridade técnica, não pela astúcia econômica, mas pelo amor, o amor fraternal" (p. 251), teria propiciado a criação de uma grande comunidade de povos irmanados por um sentir comum de que a língua seria expressão.

Faraco vê com ceticismo ambos os posicionamentos, argumentando (e bem, em nosso entender), que não há línguas superiores a outras, se analisadas por critérios puramente linguísticos, e que, como tal, o Português não pode reclamar ser um idioma mais "puro" do que qualquer outro e, por isso, destinado a uma missão civilizadora de outros povos. Por outro lado, o autor faz eco das palavras de Eduardo Lourenço, sustentando que "a ideia de o colonizador português ter sido, pela sua plasticidade, o mediador providencial entre o europeu e o exótico tropical não passa de uma mitificação que traduz um complexo de inferioridade cultural transfigurada em apologia delirante" (p. 275).

No entanto, segundo o autor, é a partir destes "topos de orgulho", apesar de dificilmente sustentáveis quando submetidos a uma prática de análise desapaixonada, que emergem os fundamentos para a criação de uma Comunidade de Países de Língua Portuguesa (CPLP). Na sua génese encontram-se o pensamento de Agostinho da Silva ("O Professor Agostinho (...) entendia que era importante fazermos uma política de unidade, de fundamento da nossa língua comum. E isso foi uma abordagem que passou a ser feita e que chegou, inclusive, à Comunidade dos Países de Língua Portuguesa, a CPLP" (p. 244) e a lúcida análise de Freyre sobre o caráter pluricêntrico da língua portuguesa, "a mesma língua, embora com linguagens as mais diversas - nacionais, subnacionais, regionais, populares - a enriquecerem, avivarem e movimentarem essa língua comum e essa cultura ao mesmo tempo una e plural" (p. 265).

A CPLP viria efetivamente a constituir-se em 1996, congregando os então oito países de língua oficial portuguesa que, "apelando aos aspectos históricos, culturais, linguísticos que (...) compartilham, decidem se congregar numa organização internacional voltada para o cumprimento de três grandes objetivos: a concertação político-diplomática, a cooperação em todos os domínios e a promoção e difusão da língua portuguesa" (p. 303). Porém, se o projeto encontrou no presidente da República Portuguesa à época - Mário Soares - um fervoroso defensor, não logrou despertar entusiasmo equivalente nos demais países parceiros que inicialmente não elegeram a comunidade como uma das prioridades das suas políticas externas. Tal apreciação leva o linguista brasileiro a expressar um sentimento de desconfiança e desalento relativo à eficácia da CPLP por considerar que há poucas "possibilidades de a CPLP se afirmar como um organismo internacional para além da retórica sentimental, mesmo considerando que há um potencial inexplorado de cooperação entre os países de língua portuguesa" (p. 308). 
Ceticismo ainda maior expressa em relação ao conceito de "Lusofonia". Afetado por um preconceito comum a outros autores igualmente desfavoráveis ao vocábulo e ao universo que ele evoca, Faraco defende que se trata de um termo cunhado por portugueses para servir os interesses de Portugal, "não [conseguindo] (...) alcançar ressonâncias nos demais países de língua oficial portuguesa", sendo "praticamente inexistente no Brasil" e "visto com grandes desconfianças nos países africanos" (p. 315); o autor não acrescenta informação sobre a sua aceitação e presença em Timor-Leste.

Os argumentos apresentados para justificar a pretensa inoperância e inadequação do termo são basicamente os seguintes: 1) trata-se de uma tentativa de fazer face à "nostalgia do império perdido", funcionando como "uma vingança sobre o fenómeno conhecido por descolonização" (p. 320); 2) nos países em que o Português não é língua nacional hegemónica pode ter um efeito glotofágico; 3 ) ignora a deriva que o Português vem sofrendo em Portugal e no Brasil, o que leva alguns linguistas a considerar que se trata já de duas línguas e não de uma só com duas variedades diferentes.

Muitas razões poderiam ser invocadas para contrariar tais argumentos. Atente-se, por exemplo, que o primeiro parece querer fazer crer que o legado da língua foi uma imposição do antigo colonizador e não uma escolha livre e autónoma dos povos autodeterminados; o segundo faz tábua rasa dos direitos consagrados nas leis dos diversos países sobre as línguas nacionais e das políticas levadas a cabo para a implementação de currículos bilingues nos países africanos e em Timor; a última hipostasia diferenças que efetivamente existem, sobretudo a nível dos discursos orais, sem no entanto ter em conta as confluências que logo se impõem quando se considera o código escrito.

Outra falácia vastas vezes evocada, e de que Faraco dá conta também, é a de que a "lusofonia" remete para a "língua dos portugueses" e não para a "língua dos que falam português". A este propósito, cabe relembrar a teoria dos "círculos concêntricos", proposta por Braj Kachru para a realidade do Inglês e que se aplica igualmente ao idioma português, que é pertença da vasta comunidade para a qual é $L 1$ - inner circle (Portugal e - Brasil), L2 - outer circle (restantes países da CPLP) ou LE - expanding circle (comunidades em que é reconhecida como uma língua internacional, embora sem estatuto social diferenciado) (pp. 343-344).

Como resultado das dinâmicas demográficas e do crescente interesse que o Português tem despertado junto de comunidades onde não goza de qualquer estatuto de oficialidade, a estabilidade destes círculos tende a ser alterada, prevendo-se que em países como Angola e Moçambique se alargue o número de falantes de Português como Lı, bem assim como que o núcleo dos que o falam como LE continue em expansão. Estas seriam razões para justificar uma "esperança para o mundo da língua portuguesa", sendo sob este título, enunciado na forma de questão, que Faraco apresenta as suas conclusões.

Embora não deixando de enfatizar a relevância dos seus mais de 250 milhões de falantes, com perspetivas de quase duplicarem até ao final de século (p. 361), o autor não se coíbe de alertar para os principais desafios que se colocam à afirmação do Português enquanto língua pluricêntrica partilhada por vastas comunidades geograficamente distantes e socioeconomicamente heterogéneas. Em jeito de síntese, conclui que 
o efetivo destaque internacional futuro da língua portuguesa na galáxia das línguas dependerá de as sociedades que a falam melhorarem substancialmente seus índices socioeconômicos e culturais; sofisticarem suas economias; desenvolverem seus recursos de 'reserva gráfica' (...); e, por fim, se projectarem como referência política internacional de um conjunto de valores fundamentais para a Humanidade tais como a paz, a democracia, a justiça, a distribuição equitativa da riqueza e o equilíbrio ambiental. (p. 367)

Esta História sociopolítica da língua portuguesa, conjugando instrumentos e métodos da pesquisa académica, que levam o autor a compulsar analiticamente diversas fontes documentais referidas numa ampla bibliografia, com um posicionamento crítico que se traduz na apresentação e defesa de pontos de vista pessoais que, concorde-se ou não com eles, o autor fundamenta e justifica, constitui indubitavelmente uma leitura útil e agradável não só para linguistas e cientistas sociais, como também para um público não especializado mas interessado em conhecer a evolução da língua portuguesa e as suas diferentes dinâmicas nos espaços e contextos em que é usada, seja qual for o seu estatuto.

\section{NOTA BIOGRÁFICA}

Micaela Ramon é Professora Auxiliar do Departamento de Estudos Portugueses e Lusófonos do Instituto de Letras e Ciências Humanas da Universidade do Minho, onde leciona Literatura Portuguesa e Português como Língua Estrangeira em cursos de graduação, pós-graduação e extensão. É licenciada em ensino de Português - Francês, mestre em ensino da Língua e da Literatura Portuguesas e doutorada em Literatura Portuguesa. É investigadora do Centro de Estudos Humanísticos da Universidade do Minho (CEHUM), colaborando igualmente com o Centro de Literaturas de Expressão Portuguesa da Universidade de Lisboa (CLEPUL) em vários projetos. É diretora do Mestrado em Português Língua Não Materna e diretora-adjunta do CEHUM. É autora do livro Os sonetos amorosos de Camões e do volume II do tomo II da Obra completa. Padre António Vieira. Sermão da sexagésima e sermões da Quaresma, tendo ainda vários capítulos e artigos publicados em livros, revistas e atas de encontros, nacionais e internacionais, sobre temas ligados às áreas em que investiga e leciona.

ORCID: https://orcid.org/oooo-0003-2193-4075

Email:micaelar@ilch.uminho.pt

Morada: Instituto de Letras e Ciências Humanas da Universidade do Minho, Campus de Gualtar, 4710-057 Braga

* Submetido: 20.04 .2018

* Aceite: 07.07 .2018 